\title{
CXCR4 knockdown inhibits the growth and invasion of nasopharyngeal cancer stem cells
}

\author{
YUAN TIAN $^{1}$, YAN SONG ${ }^{1}$, WEILIANG BAI ${ }^{2}$, XIULAN MA $^{1}$ and ZHONG REN ${ }^{3}$ \\ ${ }^{1}$ The First Department of Otolaryngology (Department of Otology); ${ }^{2}$ The Second Department of Otolaryngology \\ (Department of Rhinology), Shengjing Hospital of China Medical University, Shenyang, Liaoning 110004; \\ ${ }^{3}$ Department of Otolaryngology, The First Affiliated Hospital of China Medical University, \\ Shenyang, Liaoning 110001, P.R. China
}

Received August 27, 2015; Accepted November 28, 2016

DOI: $10.3892 / 01.2017 .5694$

\begin{abstract}
Nasopharyngeal cancer is a type of malignant tumor with a high rate of incidence. Cancer stem cells are regarded as one of the main causes for the formation and recurrence of nasopharyngeal cancer. CXC chemokine receptor type 4 (CXCR4) has been reported to perform an important role in cancer; however, the association between CXCR4 and nasopharyngeal cancer stem cells remains unclear. The present study explored the effect of CXCR4 on cellular viability, apoptosis and invasion of nasopharyngeal cancer stem cells. Results of the present study demonstrated that knockdown of CXCR4 inhibited the viability and invasion of nasopharyngeal cancer stem cells and promoted cellular apoptosis. Further studies have revealed that the anti-tumor effect of CXCR4 knockdown was associated with the inhibition of the protein kinase B signal. These results demonstrate that the knockdown of CXCR4 resulted in an anti-tumor effect in nasopharyngeal cancer stem cells. Therefore, CXCR4 may become a promising therapeutic target in the treatment of nasopharyngeal cancer.
\end{abstract}

\section{Introduction}

Nasopharyngeal cancer is a prevalent malignant tumor with a high rate of incidence in China and Southeast Asia (1-3), however the incidence of nasopharyngeal cancer is low in western countries $(3,4)$. Metastasis to the lymph nodes or to the bone, lung and liver often occurs in patients with nasopharyngeal cancer $(5,6)$, which is the main cause of mortality and also serves as a marker for poor prognosis.

Cancer stem cells are a type of cancer cells that possess the biological characteristics of stem cells. They are resistant to

Correspondence to: Dr Zhong Ren, Department of Otolaryngology, The First Affiliated Hospital of China Medical University, 155 North Nanjing Street, Shenyang, Liaoning 110001, P.R. China

E-mail: eartian@163.com

Key words: CXC chemokine receptor type 4, viability, apoptosis, invasion, protein kinase B, nasopharyngeal cancer stem cells cellular apoptosis, and thus have tolerance to chemotherapy and radiotherapy (7). Cancer stem cells are regarded as a main cause for the formation and the recurrence of nasopharyngeal cancer.

CXC chemokine receptor 4 (CXCR4) is a receptor of stromal cell-derived factor-1 (SDF-1). CXCR4 is overexpressed in various types of cancer, including esophageal and renal cell carcinoma $(8,9)$, and has a close association with the proliferation, metastasis, angiogenesis and tolerance induction of cancer cells (10-17). CXCR4 is expressed at high levels in nasopharyngeal cancer (18). Previous studies have demonstrated that CXCR4 has a close association with the growth and metastasis of nasopharyngeal cancer (19), and is also associated with the poor survival rate associated with nasopharyngeal cancer (18).

There are numerous studies that have focused on the effect that CXCR4 has on various types of tumor. However, the association between CXCR4 and nasopharyngeal cancer stem cells remains to be elucidated. The present study investigated the effect of CXCR4 knockdown on the viability, apoptosis and invasion of nasopharyngeal cancer stem cells. The results of the present study lay the theoretical basis for the additional study of cancer stem cells and also provide a novel therapeutic target for the treatment of nasopharyngeal cancer.

\section{Materials and methods}

Cell culture. The human nasopharyngeal carcinoma CNE-2 cell line was obtained from the Type Culture Collection Center of Chinese Academy of Science (Shanghai, China). Cells were cultured in RPMI-1640 media (Gibco; Thermo Fisher Scientific, Inc., Waltham, MA, USA) supplemented with $10 \%$ fetal bovine serum (FBS; Hyclone; GE Healthcare Life Sciences, Logan, UT, USA) and maintained in a cell incubator with a humidified atmosphere at $37^{\circ} \mathrm{C}$ with $5 \% \mathrm{CO}_{2}$.

Magnetic activated cell sorting (MACS) and identification. The prominin 1 (CD133) antibody serves as a specific surface marker of nasopharyngeal cancer stem cells (20). MACS was performed using a Mini \& MidiMACS Starting kit (MiltenyiBiotec $\mathrm{GmbH}$, Bergisch Gladbach, Germany). A total of $1 \times 10^{8}$ cells were collected and resuspended in a mixture of $300 \mu \mathrm{l}$ buffer, $100 \mu \mathrm{l} \mathrm{FcR} \mathrm{blocking} \mathrm{reagent} \mathrm{and}$ $100 \mu 1$ CD133 magnetic beads (CD133 Microbead kit; 
Miltenyi Biotech $\mathrm{GmbH})$. Following incubation at $4{ }^{\circ} \mathrm{C}$ for $30 \mathrm{~min}$, this mixture was added into the sorting column that was placed in the MACS separator. When the solution in the sorting column had drained, $1 \mathrm{ml}$ of buffer was added into the sorting column twice. The sorting column was then removed from the MACS separator, and $5 \mathrm{ml}$ of buffer was added into the sorting column to harvest the isolated $\mathrm{CD} 133^{+}$ CNE- 2 cells. The isolated $\mathrm{CD} 133^{+} \mathrm{CNE}-2$ cells were cultured in RPMI-1640 media with 10\% FBS and maintained in a humidified atmosphere containing $5 \% \mathrm{CO}_{2}$ at $37^{\circ} \mathrm{C}$ for further growth. Following isolation and culture, the isolated cells were identified using flow cytometry. The cells were collected and incubated with a phycoerythrin-labeled CD133 antibody (1 $\mu \mathrm{g}$; cat. no., 130-080-901; MiltenyiBiotec $\mathrm{GmbH})$ at $4^{\circ} \mathrm{C}$ for $10 \mathrm{~min}$ in the dark. Following washing with washing buffer, the cells were treated with $1 \%$ paraformaldehyde. The cells were then analyzed using a FACSCalibur flow cytometer (BD Biosciences, Franklin Lakes, NJ, USA).

Transfection. Recombinant adenovirus containing specific short hairpin RNA (shRNA) for CXCR4 or the negative control was obtained from Hanbio Biotechnology (Shanghai, China). The sequence of shRNA and the negative control is presented in Table I. CD133 ${ }^{+} \mathrm{CNE}-2$ cells were seeded into a 6 -well plate $\left(1 \times 10^{5}\right.$ cells/well) and cultured in a $37^{\circ} \mathrm{C}$ incubator for $24 \mathrm{~h}$. Subsequently, RPMI-1640 media containing the suitable adenovirus was added into each well and the cells were incubated in a $37^{\circ} \mathrm{C}$ incubator for an additional $24 \mathrm{~h}$. The cell media was then changed to fresh RPMI-1640 media and cells were collected for subsequent experiments.

Groups. Cells were divided into 3 groups: i) Isolated CD133+ CNE-2 cells (CD133+ CNE-2); ii) $\mathrm{CD}^{+} 33^{+} \mathrm{CNE}-2$ cells transfected with CXCR4 shRNA (CXCR4 shRNA); iii) $\mathrm{CD}_{133^{+}}$ CNE-2 cells transfected with negative control of shRNA (negative control).

MTT assay. Subsequent to transfection, CD133+ CNE-2 cells and $\mathrm{CD} 133^{+} \mathrm{CNE}-2$ cells transfected with shRNA or the negative control were seeded into a 96 -well plate $\left(1 \times 10^{4}\right.$ cells/well $)$ in quintuplicate. Subsequent to a $48 \mathrm{~h}$ culture, $0.2 \mathrm{mg} / \mathrm{ml}$ MTT (Sigma-Aldrich; Merck Millipore, Darmstadt, Germany) was added into each well and incubated at $37^{\circ} \mathrm{C}$ for an additional $4 \mathrm{~h}$. Following centrifugation at $112 \times \mathrm{g}$ for $10 \mathrm{~min}$ at room temperature, the supernatant was gently removed, $200 \mu \mathrm{l}$ of dimethyl sulfoxide (Sigma-Aldrich; Merck Millipore) was added into each well and the absorbance at $490 \mathrm{~nm}$ was measured with a microplate reader (Biotek Instruments, Inc., Winooski, VT, USA).

Apoptosis assay. Subsequent to transfection with either shRNA or the negative control, cells were collected for an apoptosis assay using an apoptosis detection kit (KeyGenBiotech Co., Ltd., Nanjing, China). Cells were washed with PBS and resuspended in $500 \mu \mathrm{l}$ of binding buffer. Subsequently, $5 \mu \mathrm{l}$ of Annexin V-fluorescein isothiocyanate (FITC) and $5 \mu \mathrm{l}$ of propidium iodide were added into the cell suspension and incubated at room temperature for $15 \mathrm{~min}$ in the dark. The apoptosis level of cells in each group was measured using BD FACSCalibur flow cytometer.
Matrigel assay. Matrigel (BD Biosciences) was diluted in 2-fold volume of serum-free media and Transwell chambers (Corning Incorporated, Corning, NY, USA) were precoated with the diluted Matrigel. Subsequent to transfection, cells in each group were resuspended in serum-free media to make a cell suspension $\left(2.5 \times 10^{5}\right.$ cells $\left./ \mathrm{ml}\right)$. Subsequently, $200 \mu \mathrm{l}$ of cell suspension was seeded into the upper chamber and $800 \mu \mathrm{l}$ of media containing $20 \%$ FBS was added to the lower chambers. The chambers were incubated in a $37^{\circ} \mathrm{C}$ cell incubator for $24 \mathrm{~h}$. Cells above the micropore membranes were then removed using cotton swabs and cells below the micropore membranes were fixed with $4 \%$ paraformaldehyde and stained with hematoxylin. Images of cells in each group were captured with x200 magnification, the average number of cells passing through the micropore membrane in 5 random views was calculated.

Western blot analysis. Following transfection, cells in each group were collected for western blot analysis. Cells were lysed in NP-40 lysis buffer (Beyotime Institute of Biotechnology, Shanghai, China) with $1 \%$ phenylmethanesulfonyl fluoride (Beyotime Institute of Biotechnology). The protein concentration was measured using a BCA protein assay kit (Beyotime Institute of Biotechnology). Equal amount of protein from each group was subjected to 7 or $10 \%$ SDS-PAGE. The separated proteins were transferred to polyvinylidene fluoride membranes (Merck Millipore). Subsequent to blocking with 5\% skim milk or $5 \%$ bovine serum albumin (Beijing Solarbio Science \& Technology Co., Ltd., Beijing, China), the membranes were incubated with the corresponding primary antibodies against CXCR4 (cat. no., BA0761; dilution, 1:400; Boster Systems, Inc., Wuhan, China), AKT cat. no., bs1810; dilution, 1:1,000; Bioworld Technology, Inc., Atlanta, GA, USA), phosphorylated (p)-AKT cat. no., bs4009; dilution, 1:1,000; Bioworld Technology,) and $\beta$-actin (cat. no., WL0001; dilution, 1:1,000; Wanleibio, Shenyang, China) at $4^{\circ} \mathrm{C}$ overnight. Subsequent to washing with Tris-buffered saline with Tween-20, the membranes were incubated with corresponding horseradish peroxidase (HRP)-conjugated secondary antibodies (cat. no., A0208; dilution, 1:5,000; Beyotime Institute of Biotechnology) at $37^{\circ} \mathrm{C}$ for $45 \mathrm{~min}$. The signal of the target protein was visualized using an enhanced chemiluminescence detection system (7sea Biotech, Shanghai, China) and the grayscale of target protein was analyzed using Gel-Pro-Analyzer version 4.0 software (Media Cybernetics, Inc., Rockville, MD, USA). The relative expression level of proteins was normalized to $\beta$-actin.

Immunocytochemistry. Cells from each group were cultured on coverslips, fixed with $4 \%$ formalin and permeabilized with $0.1 \%$ TritonX-100. The coverslips were then treated with $3 \%$ $\mathrm{H}_{2} \mathrm{O}_{2}$ for 15 min to inactivate endogenous peroxidase. Subsequent to blocking with normal goat serum (Beijing Solarbio Science \& Technology Co., Ltd), the cells were incubated with primary antibody against AKT or p-AKT (dilution, 1:100) at $4^{\circ} \mathrm{C}$ overnight. The cells were then incubated with biotin labeled secondary antibody (cat. no., A0277; dilution, 1:200; Beyotime Institute of Biotechnology) at room temperature for 60 min and HRP labeled streptavidin (cat. no., A0303; dilution, 1:200; Beyotime Institute of Biotechnology) at $37^{\circ} \mathrm{C}$ for $30 \mathrm{~min}$. The cells were incubated with a 3,3'-diaminobenzidine detection system (Beijing Solarbio Science and Technology 
Table I. Sequence of shRNA and its corresponding negative control (5'-3').

Forward primer (5'-3')

Reverse primer $\left(5^{\prime}-3^{\prime}\right)$

\begin{tabular}{lll}
\hline shRNA & GATCCCCGACCACAGTCATCCTCATCTTCAAGA & AATTAAAAAGACCACAGTCATCCTCATCTCT \\
& GAGATGAGGATGACTGTGGTCTTTTT & CTTGAAGATGAGGATGACTGTGGTCGGG \\
Negative & GATCCCCTTCTCCGAACGTGTCACGTTTCAAGA & AATTAAAAATTCTCCGAACGTGTCACGTTC \\
control & GAACGTGACACGTTCGGAGAATTTTT & TCTTGAAACGTGACACGTTCGGAGAAGGG
\end{tabular}

shRNA, short hairpin RNA.
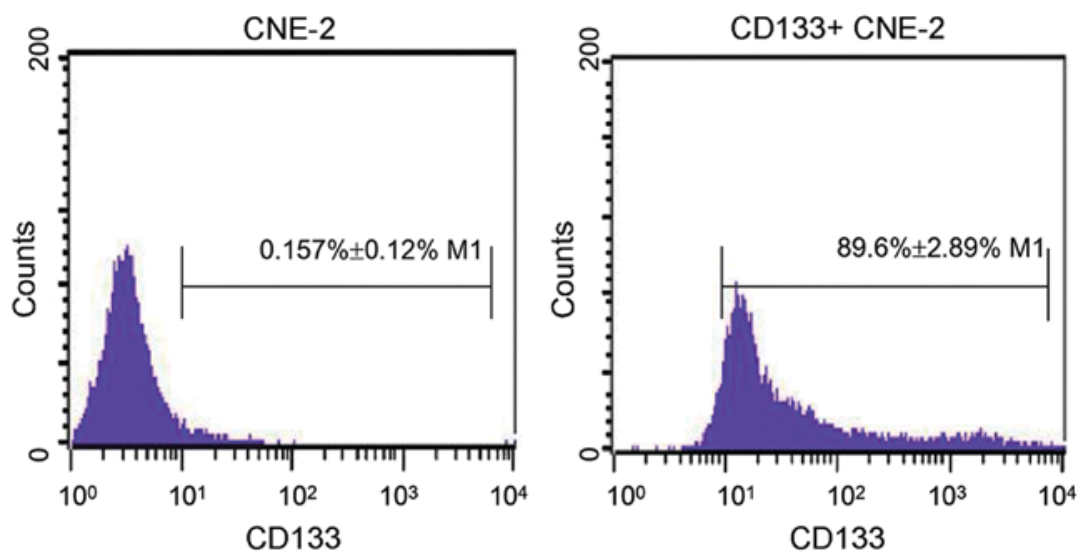

Figure 1. Identification of nasopharyngeal cancer stem cells. Following isolation by magnetic activated cell sorting, the isolated CD133 ${ }^{+} \mathrm{CNE}-2$ cells were identified by flow cytometry. Each experiment was repeated 3 times and the typical result is presented. Data are presented as the mean \pm standard deviation. CD133, prominin 1.

Co., Ltd.) and counterstained with hematoxylin. The cells were observed by optical microscopy and images were captured.

Statistical analysis. Each experiment was performed 3 times. The data are presented as the mean \pm standard deviation. Differences between groups were analyzed using a one-way analysis of variance. $\mathrm{P}<0.05$ was considered to indicate a statistically significant difference.

\section{Results}

Identification of nasopharyngeal cancer stem cells. Following the isolation of $\mathrm{CD} 133^{+} \mathrm{CNE} 2$ cells by MACS, CD133 ${ }^{+} \mathrm{CNE} 2$ cells were identified using flow cytometry. As shown in Fig. 1, there were $0.157 \pm 0.12 \% \mathrm{CD} 33^{+}$cells in normal CNE- 2 cells. However, following isolation by MACS, the percentage of CD133 ${ }^{+}$ cells increased to $89.6 \pm 2.89 \%$ ( $\mathrm{P}=0.0018)$. This result revealed that the isolated cells were nasopharyngeal cancer stem cells.

CXCR4 shRNA inhibited the growth of nasopharyngeal cancer stem cells. To explore the effect of CXCR4, a CXCR4 specific shRNA was used. Subsequent to transfection with CXCR4 shRNA, the protein level of CXCR4 was detected by western blot analysis. As shown in Fig. 2, the CXCR4 protein level was decreased to $25 \pm 3 \%$ following transfection with CXCR4 shRNA $(\mathrm{P}<0.0001)$. These results demonstrate that CXCR4 shRNA may effectively decrease the CXCR4 level.

An MTT assay was then performed to evaluate the effect of CXCR4 shRNA on the viability of nasopharyngeal cancer stem cells. Following transfection with CXCR4 shRNA, the viability of nasopharyngeal cancer stem cells was significantly inhibited comparing with cells transfected with the negative control (Fig. 3A, P=0.0079).

Apoptosis is a key factor that influences the growth of cells. In the present study, the effect of CXCR4 shRNA on cell apoptosis was investigated. Results of apoptosis assay revealed that the apoptosis level of nasopharyngeal cancer stem cells was increased significantly following transfection with CXCR4 shRNA, particularly in the phase of early apoptosis (Fig. 3B, $\mathrm{P}<0.001)$. These results were consistent with the results of the MTT assay. The afore mentioned results demonstrate that CXCR4 shRNA inhibited the growth of nasopharyngeal cancer stem cells.

CXCR4 shRNA inhibited the invasion of nasopharyngeal cancer stem cells. Migration is an important event in the progression of a tumor. The present study investigated the effect of CXCR4 shRNA on the invasion of nasopharyngeal cancer stem cells. Results of the Matrigel assay demonstrated that following transfection with CXCR4 shRNA, the number of cells passing through a micropore was decreased (Fig. 4, P=0.0057), which indicates a decrease in the invasion capability of cells. These results demonstrate that $\mathrm{CXCR} 4$ shRNA inhibited the invasion capability of nasopharyngeal cancer stem cells.

CXCR4 shRNA inhibited the AKT signal. The AKT signal has a close association with the proliferation and invasion of cells. Therefore, the present study explored the effect of CXCR4 

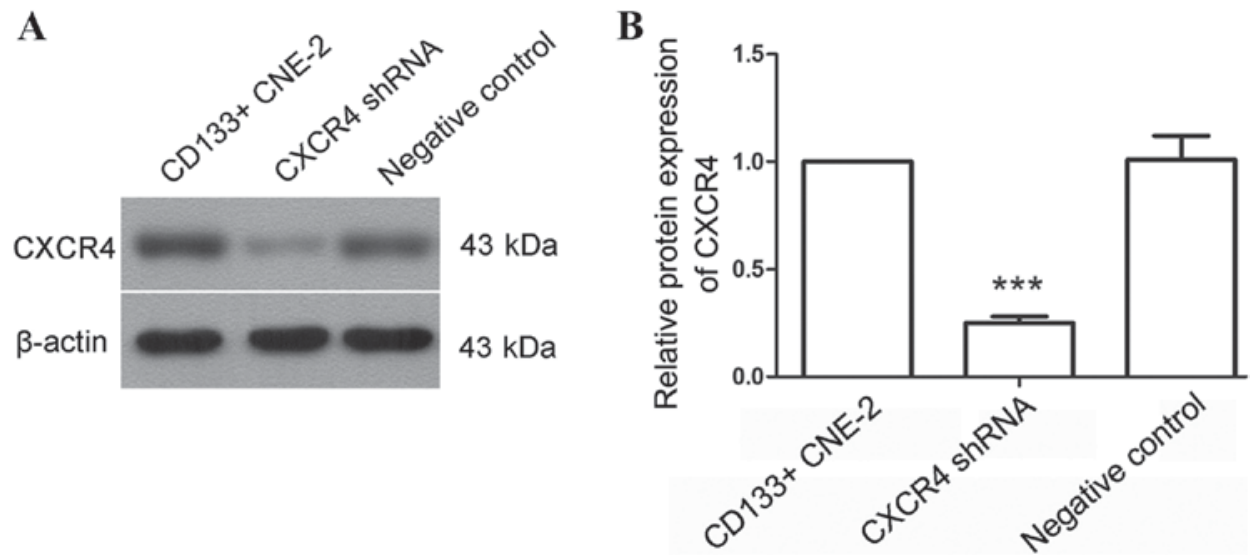

Figure 2. CXCR4 shRNA decreases the level of CXCR4 in nasopharyngeal cancer stem cells. (A) Following transfection with CXCR4 specific shRNA, the protein level of CXCR4 in nasopharyngeal cancer stem cells was detected by western blot analysis. (B) The relative expression level of CXCR4 was calculated and $\beta$-actin was used as an internal reference. Each experiment was repeated 3 times. Typical results were presented and the data are presented as the mean \pm standard deviation. ${ }^{* * *} \mathrm{P}<0.001$ compared with cells transfected with the negative control. CXCR4, CXC chemokine receptor 4; shRNA, short hairpin RNA; CD133, prominin 1.

A

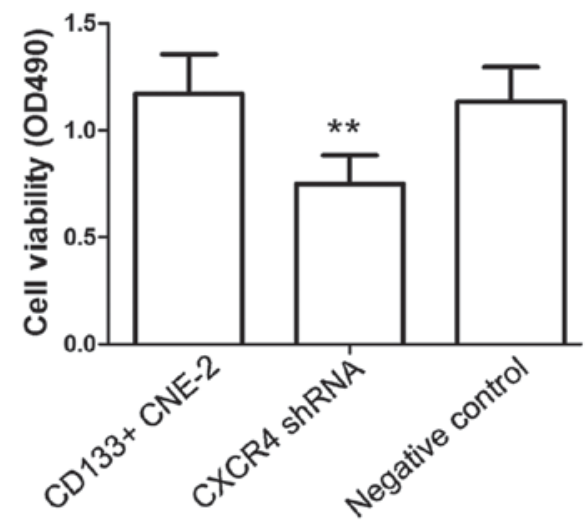

B
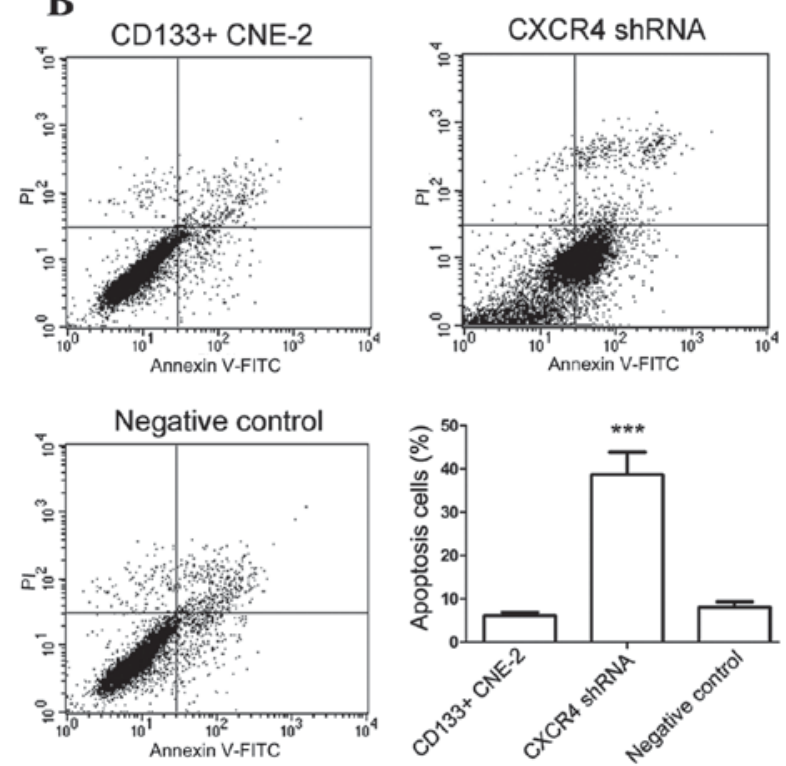

Figure 3. Knockdown of CXCR4 inhibits the growth of nasopharyngeal cancer stem cells. (A) Cellular viability was detected by MTT assay subsequent to transfection with CXCR4 shRNA. (B) Following transfection with CXCR4 shRNA, cell apoptosis was evaluated by flow cytometry. All experiments were repeated 3 times and the results are presented as the mean \pm standard deviation. ${ }^{* *} \mathrm{P}<0.01,{ }^{* * *} \mathrm{P}<0.001$ compared with cells transfected with the negative control. CXCR4, CXC chemokine receptor 4; shRNA, short hairpin RNA; CD133, prominin 1; FITC, fluorescein isothiocyanate; PI, propidium iodide.
shRNA on the activation of AKT in nasopharyngeal cancer stem cells. The protein levels of AKT and phosphorylated AKT were detected using western blot analysis. Results of the western blot analysis revealed that following transfection with CXCR4 shRNA, the protein level of phosphorylated AKT was decreased (Fig. 5A and $\mathrm{B}, \mathrm{P}=0.0182$ ). These results indicate that activation of the AKT signal was inhibited by CXCR4 shRNA transfection in nasopharyngeal cancer stem cells.

Immunocytochemistry was also performed to evaluate changes in the AKT signal. As shown in Fig. 5C, following transfection with CXCR4 shRNA, the protein level of phosphorylated AKT was decreased compared with cells transfected with negative control. These results are consistent with the results of the western blot analysis and demonstrate that CXCR4 shRNA inhibited the growth and invasion of nasopharyngeal cancer stem cells. The effect of CXCR4 shRNA may be associated with the inhibition of AKT activation, however additional investigation is required.

\section{Discussion}

The present study explored the effect of CXCR4 on the growth and invasion of nasopharyngeal cancer stem cells. It was identified that knockdown of CXCR4 inhibited the viability and invasion of nasopharyngeal cancer stem cells, and promoted cellular apoptosis. Additional study into the mechanism underlying this revealed that the inhibition of cellular growth and invasion, as a result of CXCR4 knockdown, may be associated with the inhibition of AKT signal activation.

Cancer stem cells are a minor subpopulation of cancer cells that have similar characteristics to tissue stem cells $(21,22)$. Cancer stem cells possess the ability to grow, differentiate and metastasize quickly $(21,23,24)$. As a result of these properties, cancer stem cells are regarded as a key factor that leads to tumor recurrence $(21,22)$. In the present study, CD133 ${ }^{+}$nasopharyngeal cancer cells were isolated and identified. If these cancer stem cells are not fully eradicated in the treatment of nasopharyngeal cancer, they grow quickly to form carcinoma in situ and even transfer to other locations, leading to the metastasis of nasopharyngeal cancer (21). These consequences 

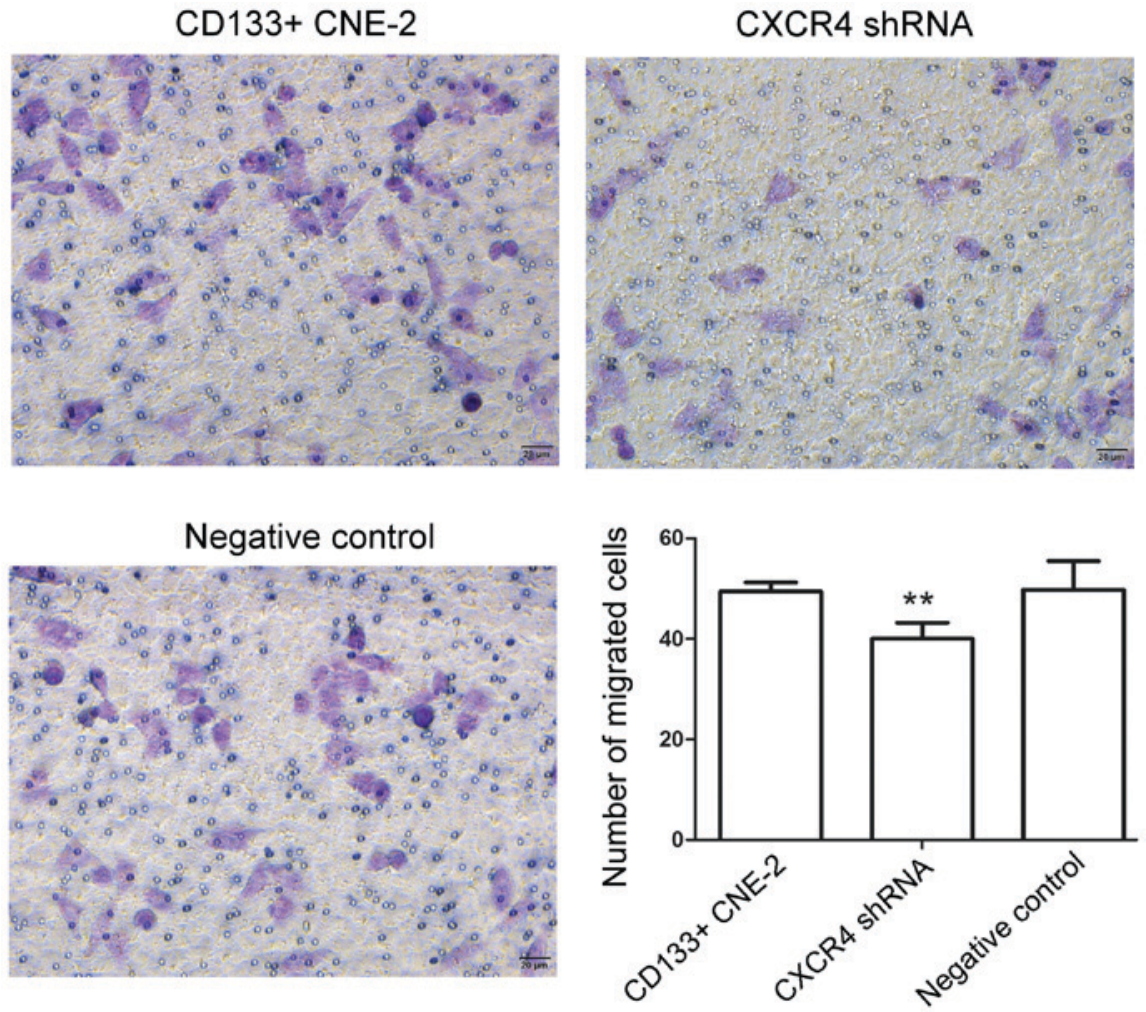

Figure 4. Knockdown of CXCR4 inhibits the invasion of nasopharyngeal cancer stem cells. Subsequent to transfection with CXCR4 shRNA, the invasion capability of nasopharyngeal cancer stem cells was evaluated using a Matrigel assay. The number of cells passing through the micropore membrane was calculated. Scale bar $=20 \mu \mathrm{m}$. All experiments were repeated 3 times and the results are presented as the mean \pm standard deviation. ${ }^{* * *} \mathrm{P}<0.01$ compared to cells transfected with the negative control. CXCR4, CXC chemokine receptor 4; shRNA, short hairpin RNA; CD133, prominin 1.
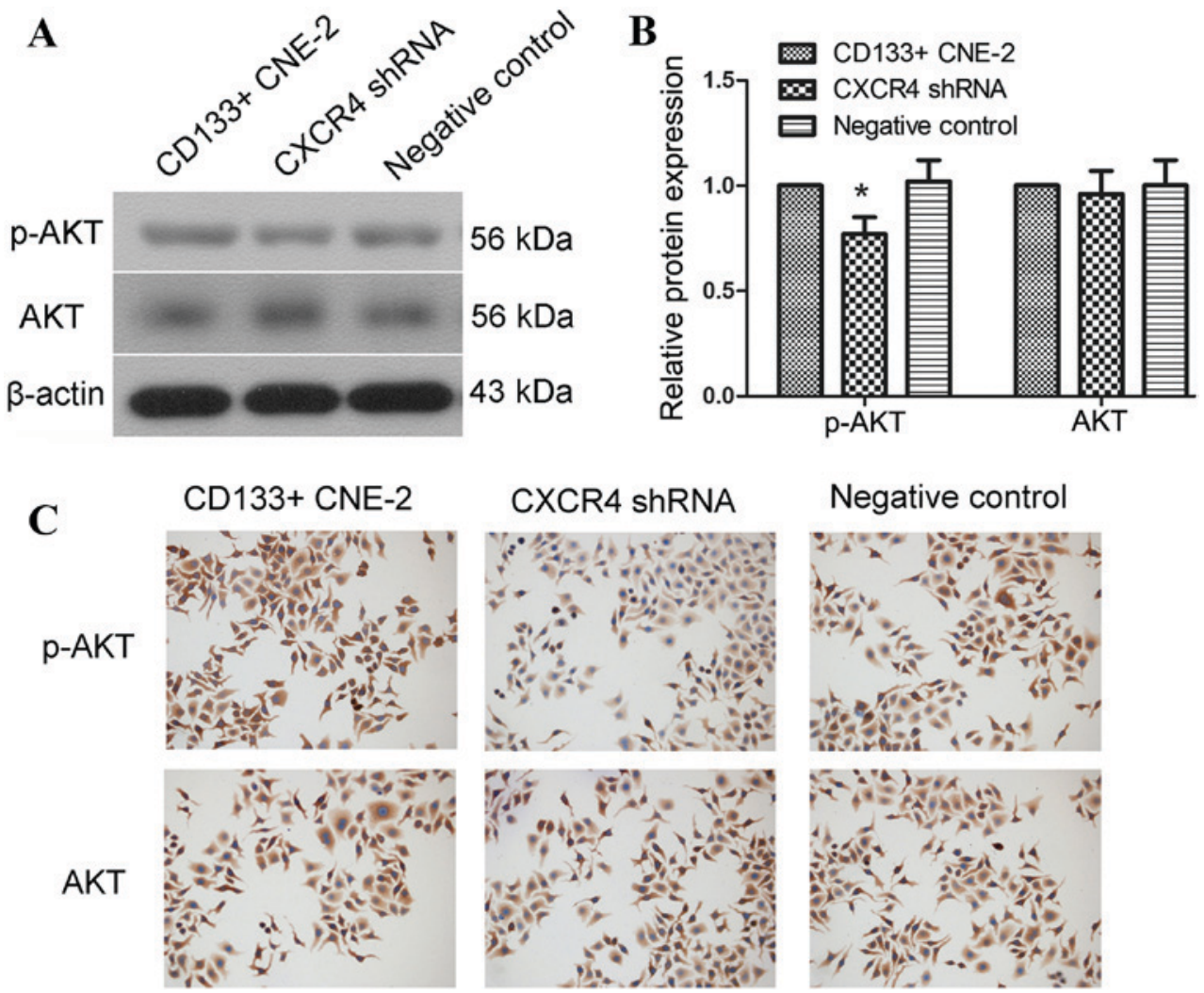

Figure 5. Knockdown of CXCR4 inhibits the activation of the AKT signal. (A) The protein level of AKT and p-AKT was detected by western blot analysis following transfection with CXCR4 shRNA. (B) The relative protein level of CXCR4 was calculated using $\beta$-actin as an internal reference. (C) The protein level of AKT and p-AKT was evaluated by immunocytochemistry. Each experiment was repeated 3 times. Typical results are presented and the results are shown as the mean \pm standard deviation. "P $<0.05$ compared to cells transfected with the negative control. CXCR4, CXC chemokine receptor 4; p-AKT, phosphorylated AKT; AKT, protein kinase B; shRNA, short hairpin RNA; CD133, prominin 1. 
are all disadvantageous to the therapy of nasopharyngeal cancer.

CXCR4 has been reported to be involved in the growth of various tumors and CXCR4 antagonists or siRNA are reported to possess anti-tumor activity. Ahmad and Amiji (21), Huang et al (6) and Porvasnik et al (11) revealed that CXCR4 antagonists inhibit tumor growth in brain, breast and prostate cancer. Smith et al (10) reported that CXCR4 antagonists or siRNA inhibited the growth of breast cancer cells. In the present study, knockdown of CXCR4 was revealed to inhibit the growth of $\mathrm{CD}_{133}{ }^{+}$nasopharyngeal cancer cells. The cell cycle and cell apoptosis are important events that have crucial effects on cell growth. Liao et al (25) demonstrated that CXCR4 regulated the protein level of cyclin and cyclin dependent kinase, thus influencing the cell cycle process. CXCR4 shRNA also showed an anti-apoptotic role in $\mathrm{CD} 133^{+}$nasopharyngeal cancer cells in the present study. These previous studies and the current results indicate that CXCR4 has an effect on the growth of nasopharyngeal cancer stem cells.

CXCR4 signaling is involved in the process of cancer metastasis. The CXCR4 signal regulates the expression of matrix metalloproteinases and the degradation of the extracellular matrix, which is critical for cellular metastasis $(26,27)$. Epigenetic silencing of CXCR4 promotes loss of cell adhesion in cervical cancer (28). CXCR4 has an influence on the epithelial-to-mesenchymal transition process, regulating the expression of E-cadherin, $\mathrm{N}$-cadherin, and vimentin $(25,29)$. CXCR4 signaling also has an influence on actin polymerization and cell skeleton rearrangement, thus regulating cellular migration $(30,31)$. Metastasis is usually the main cause of the mortality of patients with nasopharyngeal cancer. Luo et al (4) revealed that overexpression of CXCR4 is associated with the distant metastasis of nasopharyngeal cancer. The present study identified that knockdown of CXCR4 inhibited the invasion of $\mathrm{CD}_{133}{ }^{+}$nasopharyngeal cancer cells. This result indicates that CXCR4 is associated with the metastasis of nasopharyngeal cancer stem cells.

The AKT signal pathway is involved in cellular growth, differentiation and metastasis. Various studies have revealed that there is a close association between CXCR4 and the AKT signal. Zeng et al (32) demonstrated that functional inhibition of CXCR4 lead to suppression of the AKT signal. Liao et al (25) also reported that the cell cycle regulation function of CXCR4 is associated with the AKT signal. Luo et al (4) revealed that CXCR4 activated the AKT signal and promoted the motility of nasopharyngeal carcinoma cells. The present study identified that the AKT signal was involved in the regulatory function of CXCR4 in nasopharyngeal cancer stem cells, which is consistent with the report of Luo et al. In addition, mitogen activated protein kinase and nuclear factor $\kappa \mathrm{B}$ signals have also been revealed to be involved in the regulation mechanism of CXCR4 (4,25,32-34).

In conclusion, the present results demonstrate that knockdown of CXCR4 inhibited the viability and invasion of nasopharyngeal cancer stem cells and promoted cellular apoptosis. This function of CXCR4 knockdown may be associated with the inhibition of the AKT signal. CXCR4 knockdown resulted in effective inhibition of nasopharyngeal cancer stem cells in the present study. Additionally, CXCR4 is regarded as a prognostic marker of various types of cancer $(35,36)$.
Inhibition of CXCR4 was reported to sensitize cancer cells to radiotherapy and chemotherapy $(17,37)$. Taken together, results from previous studies and the present study indicate that CXCR4 may become a promising therapeutic target in the treatment of nasopharyngeal cancer.

\section{References}

1. Cao SM, Simons MJ and Qian CN: The prevalence and prevention of nasopharyngeal carcinoma in China. Chin J Cancer 30: 114-119, 2011.

2. Segawa Y, Oda Y, Yamamoto H, Shiratsuchi H, Hirakawa N, Komune S and Tsuneyoshi M: Close correlation between CXCR4 and VEGF expression and their prognostic implications in nasopharyngeal carcinoma. Oncol Rep 21: 1197-1202, 2009.

3. Yu MC and Yuan JM: Epidemiology of nasopharyngeal carcinoma. Semin Cancer Biol 12: 421-429, 2002.

4. Luo DH, Chen QY, Liu H, Xu LH, Zhang HZ, Zhang L, Tang LQ, Mo HY, Huang PY, Guo X and Mai HQ: The independent, unfavorable prognostic factors endothelin A receptor and chemokine receptor 4 have a close relationship in promoting the motility of nasopharyngeal carcinoma cells via the activation of AKT and MAPK pathways. J Transl Med 11: 203, 2013.

5. King AD, Ahuja AT, Leung SF, Lam WW, Teo P, Chan YL and Metreweli C: Neck node metastases from nasopharyngeal carcinoma: MR imaging of patterns of disease. Head Neck 22: 275-281, 2000.

6. Huang CJ, Leung SW, Lian SL, Wang CJ, Fang FM and Ho YH: Patterns of distant metastases in nasopharyngeal carcinoma. Kaohsiung J Med Sci 12: 229-234, 1996.

7. Malik B and Nie D: Cancer stem cells and resistance to chemo and radio therapy. Front Biosci (Elite Ed) 4: 2142-2149, 2012.

8. Kaifi JT, Yekebas EF, Schurr P, Obonyo D, Wachowiak R, Busch P, Heinecke A, Pantel K and Izbicki JR: Tumor-cell homing to lymph nodes and bone marrow and CXCR4 expression in esophageal cancer. J Natl Cancer Inst 97: 1840-1847, 2005.

9. Zagzag D, Krishnamachary B, Yee H, Okuyama H, Chiriboga L, Ali MA, Melamed J and Semenza GL: Stromal cell-derived factor-1alpha and CXCR4 expression in hemangioblastoma and clear cell-renal cell carcinoma: Von Hippel-Lindau loss-of-function induces expression of a ligand and its receptor. Cancer Res 65: 6178-6188, 2005.

10. Smith MC, Luker KE, Garbow JR, Prior JL, Jackson E, Piwnica-Worms D and Luker GD: CXCR4 regulates growth of both primary and metastatic breast cancer. Cancer Res 64: 8604-8612, 2004.

11. Porvasnik S, Sakamoto N, Kusmartsev S, Eruslanov E, Kim WJ, Cao W, Urbanek C, Wong D, Goodison S and Rosser CJ: Effects of CXCR4 antagonist CTCE-9908 on prostate tumor growth. Prostate 69: 1460-1469, 2009.

12. Hassan S, Buchanan M, Jahan K, Aguilar-Mahecha A, Gaboury L, Muller WJ, Alsawafi Y, Mourskaia AA, Siegel PM, Salvucci $\mathrm{O}$ and Basik M: CXCR4 peptide antagonist inhibits primary breast tumor growth, metastasis and enhances the efficacy of anti-VEGF treatment or docetaxel in a transgenic mouse model. Int J Cancer 129: 225-232, 2011.

13. Müller A, Homey B, Soto H, Ge N, Catron D, Buchanan ME, McClanahan T, Murphy E, Yuan W, Wagner SN, et al: Involvement of chemokine receptors in breast cancer metastasis. Nature 410: 50-56, 2001.

14. Wang Z, Ma Q, Liu Q, Yu H, Zhao L, Shen S and Yao J: Blockade of SDF-1/CXCR4 signalling inhibits pancreatic cancer progression in vitro via inactivation of canonical Wnt pathway. Br J Cancer 99: 1695-1703, 2008.

15. Zeelenberg IS, Ruuls-Van Stalle L and Roos E: The chemokine receptor CXCR4 is required for outgrowth of colon carcinoma micrometastases. Cancer Res 63: 3833-3839, 2003.

16. Liang Z, Brooks J, Willard M, Liang K, Yoon Y, Kang S and Shim H: CXCR4/CXCL12 axis promotes VEGF-mediated tumor angiogenesis through Akt signaling pathway. Biochem Biophys Res Commun 359: 716-722, 2007.

17. Domanska UM, Boer JC, Timmer-Bosscha H, van Vugt MA, Hoving HD, Kliphuis NM, Rosati S, van der Poel HG, de Jong IJ, de Vries EG and Walenkamp AM: CXCR4 inhibition enhances radiosensitivity, while inducing cancer cell mobilization in a prostate cancer mouse model. Clin Exp Metastasis 31: 829-839, 2014. 
18. Wang N, Wu QL, Fang Y, Mai HQ, Zeng MS, Shen GP, Hou JH and Zeng YX: Expression of chemokine receptor CXCR4 in nasopharyngeal carcinoma: Pattern of expression and correlation with clinical outcome. J Transl Med 3: 26, 2005.

19. Hu J, Deng X, Bian X, Li G, Tong Y, Li Y, Wang Q, Xin R, He X, Zhou $\mathrm{G}$, et al: The expression of functional chemokine receptor CXCR4 is associated with the metastatic potential of human nasopharyngeal carcinoma. Clin Cancer Res 11: 4658-4665, 2005.

20. Zhuang HW, Mo TT, Hou WJ, Xiong GX, Zhu XL, Fu QL and Wen WP: Biological characteristics of CD133(+) cells in nasopharyngeal carcinoma. Oncol Rep 30: 57-63, 2013.

21. Ahmad G and Amiji MM: Cancer stem cell-targeted therapeutics and delivery strategies. Expert Opin Drug Deliv 1-12: 2016 (Epub ahead of print).

22. Deshmukh A, Deshpande K, Arfuso F, Newsholme P and Dharmarajan A: Cancer stem cell metabolism: A potential target for cancer therapy. Mol Cancer 15: 69, 2016.

23. Savage P: Chemotherapy curable malignancies and cancer stem cells: A biological review and hypothesis. BMC Cancer 16: 906, 2016.

24. Brabletz T, Jung A, Spaderna S, Hlubek F and Kirchner T: Opinion: Migrating cancer stem cells-an integrated concept of malignant tumour progression. Nat Rev Cancer 5: 744-749, 2005

25. Liao A, Shi R, Jiang Y, Tian S, Li P, Song F, Qu Y, Li J, Yun H and Yang X: SDF-1/CXCR4 axis regulates cell cycle progression and epithelial-mesenchymal transition via up-regulation of survivin in glioblastoma. Mol Neurobiol 53: 210-215, 2016.

26. Chinni SR, Sivalogan S, Dong Z, Filho JC, Deng X, Bonfil RD and Cher ML: CXCL12/CXCR4 signaling activates Akt-1 and MMP-9 expression in prostate cancer cells: The role of bone microenvironment-associated CXCL12. Prostate 66: 32-48, 2006.

27. Son BR, Marquez-Curtis LA, Kucia M, Wysoczynski M, Turner AR, Ratajczak J, Ratajczak MZ and JanowskaWieczorek A: Migration of bone marrow and cord blood mesenchymal stem cells in vitro is regulated by stromal-derived factor-1-CXCR4 and hepatocyte growth factor-c-met axes and involves matrix metalloproteinases. Stem Cells 24: 1254-1264, 2006.
28. Yadav SS, Prasad SB, Das M, Kumari S, Pandey LK, Singh S, Pradhan S and Narayan G: Epigenetic silencing of CXCR4 promotes loss of cell adhesion in cervical cancer. Biomed Res Int 2014: 581403, 2014.

29. Hu TH, Yao Y, Yu S, Han LL, Wang WJ, Guo H, Tian T, Ruan ZP, Kang XM, Wang J, et al: SDF-1/CXCR4 promotes epithelial-mesenchymal transition and progression of colorectal cancer by activation of the Wnt/ $\beta$-catenin signaling pathway. Cancer Lett 354: 417-426, 2014.

30. Burger JA and Kipps TJ: CXCR4: A key receptor in the crosstalk between tumor cells and their microenvironment. Blood 107: 1761-1767, 2006.

31. Domanska UM, Kruizinga RC, Nagengast WB, Timmer-Bosscha H, Huls G, de Vries EG and Walenkamp AM: A review on CXCR4/CXCL12 axis in oncology: No place to hide. Eur J Cancer 49: 219-230, 2013.

32. Zeng Z, Shi YX, Samudio IJ, Wang RY, Ling X, Frolova O, Levis M, Rubin JB, Negrin RR, Estey EH, et al: Targeting the leukemia microenvironment by CXCR4 inhibition overcomes resistance to kinase inhibitors and chemotherapy in AML. Blood 113: 6215-6224, 2009.

33. Yu T, Wu Y, Helman JI, Wen Y, Wang C and Li L: CXCR4 promotes oral squamous cell carcinoma migration and invasion through inducing expression of MMP-9 and MMP-13 via the ERK signaling pathway. Mol Cancer Res 9: 161-172, 2011.

34. Kukreja P, Abdel-Mageed AB, Mondal D, Liu K and Agrawal KC: Up-regulation of CXCR4 expression in PC-3 cells by stromal-derived factor-1alpha (CXCL12) increases endothelial adhesion and transendothelial migration: Role of MEK/ERK signaling pathway-dependent NF-kappaB activation. Cancer Res 65: 9891-9898, 2005

35. Ahn JY, Seo K, Weinberg OK and Arber DA: The prognostic value of CXCR4 in acute myeloid leukemia. Appl Immunohistochem Mol Morphol 21: 79-84, 2013.

36. Parker CC, Kim RH, Li BD and Chu QD: The chemokine receptor CXCR4 as a novel independent prognostic marker for node-positive breast cancer patients. J Surg Oncol 106: 393-398, 2012.

37. Liang S, Peng X, Li X, Yang P, Xie L, Li Y, Du C and Zhang G: Silencing of CXCR4 sensitizes triple-negative breast cancer cells to cisplatin. Oncotarget 6: 1020-1030, 2015. 